\title{
PIONEIRISMO BIBLIOGRÁFICO EM UM POLÍMETA DO SÉC. XVI: CONRAD GESNER $^{1}$
}

\section{PIONERISMO BIBLIOGRÁFICO EN UN POLÍMETA DEL SIGLO XVI: CONRAD GESNER}

\begin{abstract}
André Vieira de Freitas Araújo ${ }^{2}$ - armarius.araujo@gmail.com Doutorando em Ciência da Informação pela Universidade de São Paulo (PPGCI-ECA-USP). Professor do Curso de Biblioteconomia e Gestão de Unidades de Informação da Universidade Federal do Rio de Janeiro (CBG-UFRJ).
\end{abstract}

\section{RESUMO}

Introdução: A Bibliografia é uma disciplina constituída por interfaces teóricas e práticas que, desde sua origem, têm fundamentado o tratamento documental. Possui uma longa história, cuja eminência está nas contribuições do cientista, erudito e bibliógrafo suíço, Conrad Gesner (1516-1565), e na sua obra Bibliotheca Universalis.

Objetivo: 1) identificar as interfaces da Bibliografia, em particular a bibliotecária e material; 2) recuperar elementos constitutivos da cultura bibliográfica; 3) delinear o perfil biobibliográfico de Conrad Gesner; 4) identificar, de forma sumária, aspectos bibliográficos de Bibliotheca Universalis, do ponto de vista descritivo e semântico e 5) discutir seu sentido como dispositivo de mediação e memória bibliográfica.

Metodologia: Revisão de literatura a partir da perspectiva histórica.

Resultados: Gesner é um dos mais notáveis cientistas do período moderno, além de ser considerado o "pai da Bibliografia" e fundador da disciplina bibliográfica. Com Bibliotheca Universalis, delineou as práticas bibliográficas da Europa Moderna.

Conclusões: Bibliotheca Universalis é mais do que um produto cultural e documentário: arrola aspectos da cultura manuscrita e impressa e traz implicitamente uma profunda reflexão descritiva e semântica sobre os documentos e os saberes. Tais aspectos não só contribuem à configuração

\footnotetext{
${ }^{1}$ Este texto é uma versão revisada, modificada e ampliada do trabalho "Cultura Bibliográfica e Documento no Séc. XVI: Bibliotheca Universalis", apresentado e publicado nos Anais do III Colóquio Internacional da Rede MUSSI / III Colloque International du Réseau MUSSI, realizado em Salvador, em novembro de 2014.

${ }^{2}$ Bolsista da Coordenação de Aperfeiçoamento de Pessoal de Nível Superior (CAPES).
} 
histórica e conceitual da Bibliografia enquanto disciplina, mas, sobretudo, evidenciam o pioneirismo bibliográfico do polímeta do Séc. XVI.

Palavras-chave: Bibliografia - história e teoria. Bibliógrafos - história. Bibliotheca Universalis - Séc. XVI. Conrad Gesner - 1516-1565. Cultura bibliográfica.

\section{INTRODUÇÃO}

A Bibliografia é uma disciplina constituída por interfaces teóricas e práticas que, desde sua origem, tem fundamentado o tratamento documental, seja do ponto de vista de sua descrição, classificação, circulação e mediação. Paralelamente, a Bibliografia se ocupa do mapeamento e da representação dos saberes e do conhecimento.

No âmbito da historiografia informacional/documental, a Bibliografia precede as áreas da Documentação, Biblioteconomia e Ciência da Informação (Cl).

Portanto, ela possui uma longa história, cuja eminência está nas contribuições do cientista, erudito e bibliógrafo suíço, Conrad Gesner (1516-1565), e no seu maior projeto bibliográfico, Bibliotheca Universalis (Séc. XVI).

A obra de Conrad Gesner delineou as práticas bibliográficas da Europa Moderna, já que inúmeras bibliografias se basearam em Bibliotheca. Neste sentido, Gesner é considerado o "pai da Bibliografia" e fundador da disciplina bibliográfica.

Gesner compõe o que podemos denominar de cultura

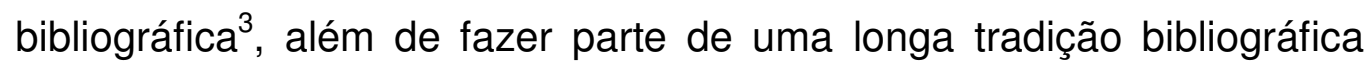
que, ao longo de seu percurso histórico, adquiriu inúmeras abordagens, aplicações e entendimentos.

\footnotetext{
${ }^{3}$ É interessante notarmos que o termo "cultura" figura no título da obra de Fiammetta Sabba (2012), professora do "Corso di Laurea Magistrale in Scienze del Libro e del Documento Università di Bologna, Campus di Ravenna" e especialista em Gesner. Cf. SABBA, Fiametta. La 'Bibliotheca Universalis' di Conrad Gesner: monumento della cultura europea. Roma: Bulzoni Editore, 2012.
} 
Esta diversidade de enfoques dificulta o estabelecimento de um consenso sobre o conceito e o escopo da Bibliografia, no entanto, sua definição englobaria duas grandes interfaces.

A primeira, ligada aos fundamentos da disciplina, está associada à produção e difusão de documentos (instrumentos) de registro, organização, representação, acesso e mediação da cultura escrita, notadamente os inventários, catálogos e bibliografias que foram produzidos e aperfeiçoados, seja na era manuscrita ou impressa. Teríamos aqui a esfera bibliotecária da Bibliografia.

As bibliografias se tornaram fontes e objetos à pesquisa histórica e mesmo filosófica sobre os fenômenos informacionais e documentais. Exemplo marcante e referencial desse tipo de investigação é a obra monumental "Storia della Bibliografia", publicada em 11 volumes e em 13 tomos, entre os anos de 1988 e 2001. Capitaneada por Alfredo Serrai ${ }^{4}$, "Storia della Bibliografia" discute a construção históricofilosófico-conceitual da Bibliografia, por meio de uma pesquisa histórica rigorosa dos produtos documentários e de seus autores, sem desconsiderar o mapeamento e a representação dos saberes e do conhecimento no contexto das ciências e das instituições. No núcleo da obra está a história dos processos informacionais e comunicacionais.

A segunda interface que auxilia na construção do conceito de Bibliografia é aquela que a entende como disciplina que se ocupa do estudo da fisicalidade do livro, considerando a ideia de que a forma do livro/documento determina o seu sentido e seus modos de apropriação. Teríamos aqui a esfera material da Bibliografia.

Nesta linha, se destacam os estudos de bibliografia descritiva e manuscritos literários de Fredson Bowers (1949) e Walter Wilson Greg (1966), de tipos móveis e impressos de Philip Gaskell (1972) e de bibliografia e sociologia dos textos de Donald F. Mckenzie (1999).

\footnotetext{
${ }^{4}$ Bibliógrafo italiano e professor emérito da "Scuola Speciale per Archivisti e Bibliotecari dell' Università 'La Sapienza' di Roma”. Como um dos teóricos contemporâneos mais relevantes da disciplina, Serrai realiza uma reflexão filosófica e histórica sobre a Bibliografia que a situa no plano das ideias e não somente dos fatos (SERRAI, 1994, 2000, 2001, 2010).
} 
Esta esfera dialoga com a Bibliologia, Colecionismo, Biblioteconomia de Livros Raros/Coleções Especiais, Preservação Documental e mesmo a História Cultural, pois destaca os aspectos intrínsecos (ligados à produção editorial/documental) e extrínsecos dos livros/documentos (ligados aos exemplares e às intervenções dos leitores), enfatizando que sua fisicalidade é a base para a compreensão de seu sentido, uso, difusão e apropriação.

As duas interfaces da Bibliografia, bibliotecária e material, mostram que a sua redução a uma simples lista de livros organizada por normas contemporâneas é drasticamente equivocada, uma vez que se trata de uma disciplina ricamente estruturada e fundamentada.

Sob a perspectiva da dimensão bibliotecária da Bibliografia e sua relação com Conrad Gesner, o presente estudo suscita algumas questões: qual é papel de Bibliotheca Universalis no contexto da cultura bibliográfica? Quais são seus aspectos bibliográficos? Que tratamento dá aos documentos listados? Podemos considerar a obra como um dispositivo de mediação e memória bibliográfica?

A partir destas questões os objetivos que norteiam este trabalho são: 1) identificar as interfaces da Bibliografia, em particular a bibliotecária e material; 2) recuperar elementos constitutivos da cultura bibliográfica; 3) delinear o perfil biobibliográfico de Conrad Gesner; 4) identificar, de forma sumária, aspectos bibliográficos de Bibliotheca Universalis, do ponto de vista descritivo e semântico e 5) discutir seu sentido como dispositivo de mediação e memória bibliográfica.

Para o alcance destes objetivos, conduzimos a revisão de literatura a partir da perspectiva histórica, no sentido de discutir os aspectos históricos, bibliográficos e documentais de Bibliotheca Universalis de forma temporal e relacional.

\section{AS INTERFACES DA BIBLIOGRAFIA}

A palavra bibliografia, derivada de duas palavras gregas, biblion (livro) e graphein (escrever), foi usada originalmente no sentido de 
"escrever livros" e, posteriormente, no de "escrever sobre livros" (FARIA; PERICÃO, 2008).

Do ato de escrever, o sentido da palavra bibliografia se estendeu para $O$ ato de descrever livros (manuscritos e impressos) e, posteriormente, mapear e representar os saberes e os conhecimentos neles contidos.

Serrai (2001) afirma que a Bibliografia é o mapa do índice, da ciência e da cultura enquanto atividade que se funda e se expressa por meio do testemunho documental.

A palavra bibliografia indica a disciplina (Bibliografia), seu objeto de estudo (ligado às teorias e aos métodos de produção de repertórios, aspectos da fisicalidade dos documentos, etc.) e o resultado dos processos documentários (as listas).

As reflexões de Serrai $(1994,2000,2001,2010)$ são relevantes para a compreensão da dinâmica flutuante da disciplina bibliográfica, cujos debates ainda não estão esgotados na contemporaneidade, exigindo novas leituras sobre antigos problemas.

Este entendimento sobre papel atual da Bibliografia como disciplina, mesmo no Séc. XXI, e que ainda "requer refundação teórica essencial" (SERRAI, 2001, p. 15) parece não ser considerado nos estudos de Documentação e $\mathrm{Cl}$, a não ser como disciplina historicamente distante e mencionada do ponto de vista meramente cronológico ${ }^{5}$.

Levantamos aqui algumas hipóteses para o fato da Bibliografia como disciplina não ser investigada e discutida na mesma perspectiva que a Documentação e a $\mathrm{Cl}$, ao menos na concepção brasileira e anglosaxã.

${ }^{5}$ Essas hipóteses exigem maior aprofundamento investigativo. Não é objetivo deste trabalho discutir as relações teóricas e históricas entre Bibliografia, Documentação e $\mathrm{Cl}$, mas nos parece inevitável, em tempos de discussões epistemológicas sobre a $\mathrm{Cl}$, situarmos o papel da Bibliografia neste processo histórico-documental-informacional. Esta ação requer o desenvolvimento dos estudos bibliográficos de forma mais retrospectiva, para além da abordagem otletiana, ou seja, estudos anteriores ao Séc. XIX. 
Comecemos pelo uso do termo bibliografia em Paul Otlet. De acordo com Ortega e Lara (2010), em relação "[...] à terminologia adotada para a área que propõe, nos artigos publicados entre 1905 e 1917, Otlet foi abandonando a palavra bibliografia em proveito das palavras documentação e informação."

Para Lund (2009), a tentativa de organizar de forma prática a documentação exigia definir exatamente o termo documento e, para tanto, Otlet precisaria redefinir a Ciência da Bibliografia. Dentro desta perspectiva, a visão otletiana sobre a Documentação teria conduzido à ultrapassagem do uso do termo bibliografia.

Em "What is a document", Buckland (1997) enfatiza que no final do Séc. XIX houve o rápido crescimento do número de publicações, especialmente científicas e técnicas. Este crescimento teria exigido maior administração das técnicas de coleta, preservação, organização, representação, seleção, reprodução e disseminação de documentos.

Para Buckland (1997), o termo tradicional para esta atividade é justamente bibliografia. Contudo, estas atividades não se comportariam mais no âmbito da bibliografia, uma vez que ela não seria mais satisfatória por duas razões: 1) notava-se que algo a mais que a tradicional bibliografia era necessário e 2) bibliografia tinha outro significado, especialmente histórico ou analítico, ligados à técnica tradicional de produção de livros.

Buckland parece desconsiderar a possibilidade de se refletir mesmo contemporaneamente sobre a Bibliografia, uma vez que é possível relacioná-la a inúmeros saberes e atividades documentárias do tempo presente. Ou seja, o "abandono" do termo, por ele citado, demonstra o desconhecimento (inclusive por parte de inúmeros autores do campo da $\mathrm{Cl}$ ) do arcabouço teórico e metodológico que a Bibliografia tem consolidado desde a sua origem.

Estas questões de ordem historiográfica são fundamentais para o entendimento da concepção e do uso do termo bibliografia pelas ciências. 
Por outro lado é inegável, do ponto de vista da história das disciplinas que lidam com a informação e com o documento, que a Bibliografia fundamentou as práticas e técnicas desenvolvidas posteriormente pela Documentação, Biblioteconomia e $\mathrm{Cl}$, sobretudo na sua dimensão documental para concepção e desenvolvimento de listas e repertórios bibliográficos.

Neste movimento observa-se que divergências e convergências conceituais entre bibliógrafos, documentalistas e, também hoje, cientistas da informação, acompanham o entendimento sobre o conceito e a natureza da Bibliografia, de modo que não há um consenso sobre sua definição.

No presente trabalho, entendemos a Bibliografia de forma ampla e atemporal, conforme a perspectiva postulada por Serrai (2001, p. 80): "A Bibliografia é [...] mãe de todas as disciplinas que estão envolvidos na organização e estruturação da comunicação escrita - no passado e hoje, registradas e transmitidas [...]."

Para o bibliógrafo italiano, a Bibliografia possui uma série de interesses especializados e conectados com a esfera - material, tecnológica, editorial, comercial, artística, colecionadora e bibliotecária que gira em torno do objeto livro, a sua gênese, sua produção, sua forma e seu conteúdo (SERRAI, 1994).

No que toca à esfera bibliotecária, aspecto de maior interesse desse trabalho, a Bibliografia dialoga com as práticas históricas e culturais de catalogação e de classificação documental, ou seja, está intimamente ligada às práticas de organização do conhecimento.

É justamente 0 debate sobre 0 passado das práticas bibliográficas que se torna uma via fundamental e necessária para a ampliação das reflexões sobre as atividades bibliográficas, documentais e informacionais, mesmo no contexto da $\mathrm{Cl}$, conforme defende Crippa (2010, p. 15-16):

[...] o olhar de escolas históricas voltadas para uma pesquisa indiciaria, como propõe Carlo Ginzburg, ou para os estudos de uma História Cultural, como no caso 
de Chartier, Darnton ou Burke, apresentam perspectivas renovadas em estudos históricos sobre as atividades bibliográficas e de catalogação [grifo nosso], propondo abordagens inéditas de análise dos sistemas de produção, seleção, organização e mediação cultural de objetos já amplamente estudados: os livros, as coleções, os registros materiais que, em algum momento, se tornaram dignos de serem preservado e disseminados para a constituição da ciência moderna. Esta história possui metodologias próprias, objeto de discussão do campo histórico, e não da Ciência da Informação, mas cujos resultados a colocam na fronteira disciplinar das duas áreas.

Pelo fato da Bibliografia também contemplar o estudo dos produtos documentários que levam o seu próprio nome, isto é, as bibliografias, estamos diante de uma disciplina chave para a investigação histórica e cultural do tratamento da informação.

\section{CULTURA BIBLIOGRÁFICA}

Como disciplina, a Bibliografia é posterior aos objetos que designa (bibliografias, listas e repertórios), uma vez que a produção de registros está diretamente ligada à origem dos equipamentos e meios de transmissão cultural e documental.

A prática de elencar, listar, registrar, selecionar e organizar faz parte de uma longa tradição cujas raízes estão associadas à era manuscrita. Tomemos duas referências significativas do mundo antigo e medieval, respectivamente: Calímaco (350 - c.240 d.C) e Cassiodoro (Séc. VI).

O conjunto de obras da Biblioteca de Alexandria constituiu a mais vasta coleção de livros da Antiguidade. A tarefa de organizá-los coube a Calímaco que:

[...] ligado à biblioteca sem ser dela o responsável efetivo, empreendeu a tarefa de recensear-lhe as riquezas. Suas Tábuas dos autores que se ilustram em todos os aspectos da cultura e de seus escritos, em 120 rolos, se prendem a um duplo projeto. Elas estão evidentemente em relação com as coleções da biblioteca, mesmo que esta não seja explicitamente mencionada no título. Embora não se trate, sem dúvida, de um catálogo no sentido estrito, essas Tábuas têm 
uma função de guia bibliográfico [grifo nosso] apto a orientar as pesquisas dos hóspedes do Museu. Seu objeto é tanto o conteúdo quanto a estrutura da biblioteca. Com efeito, essas Tábuas são recortadas em grandes rubricas - a epopéia, a retórica, os filósofos, os historiadores, os médicos, a poesia e seus diferentes gêneros, etc., que refletem talvez a repartição dos livros em diferentes armaria, ao longo do perípatos do Museu. [...] No interior de cada rubrica, os autores são enumerados por ordem alfabética, com algumas informações biográficas e a lista das obras atribuídas. Deste modo, se passaria e um princípio de classificação topográfica para um princípio convencional de catalogação. (JACOB, 2000, p. 57).

Pinakes de Calímaco equipara-se a uma bibliografia pois considera o aspecto intelectual e conteúdo formal dos documentos.

Já Cassiodoro figura entre os pioneiros da Bibliografia na Idade Média, além de possuir um perfil original que antecipou os tempos (CAPACCIONI, 2006).

Em Institutiones divinarum et saecularium litterarum (Instituições das literaturas divinas e seculares), Cassiodoro definiu o trabalho que cabia ao monge e indicou os livros necessários à sua formação. 0 tratado teve um peso e importância que por muito tempo não foi reconhecido ou observado: deu nova concepção às bibliotecas, mas, sobretudo, às práticas de leitura e dos leitores.

De fato Cassiodoro constituiu uma bibliografia: na primeira parte de Institutiones trata dos autores cristãos da Bíblia e dos comentaristas, enquanto na segunda parte dá a definição das sete artes liberais e os livros correspondentes a cada arte (RICHÉ, 2000).

No prefácio da obra, a distinção de Boécio para o conhecimento entre as sete artes liberais foi preservada, mas retórica e dialética receberam amplo tratamento. As citações feitas nesse trabalho revelaram a biblioteca adequada para o mosteiro: seria significante que as obras de cosmografia, geografia, retórica, e literatura clássica tivessem lugar nas prateleiras da biblioteca, mas que não estivessem sobre a parte das Sagradas Escrituras, escritos patrísticos e histórias da 
Igreja. Os livros estariam guardados em nove prateleiras, e organizados não por autores, mas sim por assuntos (THOMPSON, 1939).

Para Capaccioni (2006, p. 11), Calímaco e Cassiodoro suscitam uma questão que ainda continua a dividir os estudiosos: "[...] a Bibliografia é filha da Imprensa ou nasce de uma primordial exigência de comunicação do homem e, ainda, dispensa tecnologias específicas?"

É inegável que a Imprensa teve como um dos seus mais significativos impactos a vasta produção de bibliografias, como meios de registro, organização, seleção, disponibilização e mediação da cultura escrita para uma comunidade de estudiosos e eruditos.

A Imprensa também alavancou a percepção da fisicalidade do livro. No entanto, os inventários da era manuscrita, mesmo carentes de "detalhes bibliográficos", representariam a própria gênese da Bibliografia.

Portanto, a organização e representação dos saberes já estava presente desde o mundo antigo e medieval, mas é na formação da Europa Moderna que se busca uma sistemática bibliográfica.

As primeiras reflexões sobre a Bibliografia deram-se no inicio da era moderna, quando houve a expansão da figura dos humanistas: interessados pelos textos antigos e pelos modos em que os mesmos deveriam ser organizados, muitos se dedicaram não só à classificação dos seres, mas também dos saberes. Nos bibliógrafos modernos havia uma postura de dissecação dos elementos das ciências naturais que se transferiu para a dissecação do conhecimento, constituindo-se a ideia de uma anatomia do conhecimento.

A primeira bibliografia sistemática publicada, Liber de scriptoribus ecclesiasticis (1494), é de autoria de Johannes Trithemius (1462-1516). Foi o primeiro repertório biobibliográfico da Idade Moderna que, embora tenha esse título, não se limita às obras de escritores eclesiásticos no sentido estrito mas, no âmbito da civilização cristã, incorpora escritos filosóficos, científicos e literários (SERRAI, 1997).

Inúmeros bibliógrafos espalham-se pela Europa não só preocupados com a "ordem dos livros", mas também com a 
representação do conhecimento por meio de bibliografias e catálogos (CHARTIER, 1998).

É neste contexto cultural, dos primeiros anos da Europa Moderna, que floresce o "pai da Bibliografia" e fundador da disciplina bibliográfica: Conrad Gesner.

\section{O BIBLIÓGRAFO POLÍMETA E SUA OBRA: CONRAD GESNER E BIBLIOTHECA UNIVERSALIS (SÉC. XVI)}

Conrad Gesner (1516-1565; FIG. 1) publicou livros sobre assuntos diversos, como linguística, medicina, teologia, botânica, zoologia, paleontologia e mineralogia. Foi um dos mais notáveis cientistas do período moderno.

Seus múltiplos interesses delinearam o perfil de sua biblioteca, constituída por obras de história, línguas e literatura, filosofia, medicina, farmacologia, ciências naturais, teologia e miscelâneas (LEO; KELLER; WEIDMANN, 2008).

De acordo com Fiammetta Sabba (2012), a atividade científicoerudita de Gesner, a partir de sua biografia,

[...] pode ser construída em torno de duas fases distintas: 1) a fase de formação em que estão incluídos os estudos clássicos, a aplicação na Medicina, o exercício da profissão, e o interesse pela Botânica [...] 2) a fase madura, ou seja, da produção científica de: a) obras bibliográficas b) obras linguístico-filológicas c) obras médicas, físicas e de ciências naturais. (SABBA, 2012, p. 30). 
Figura 1 - Conrad Gesner (por Tobias Stimmer, 1564)

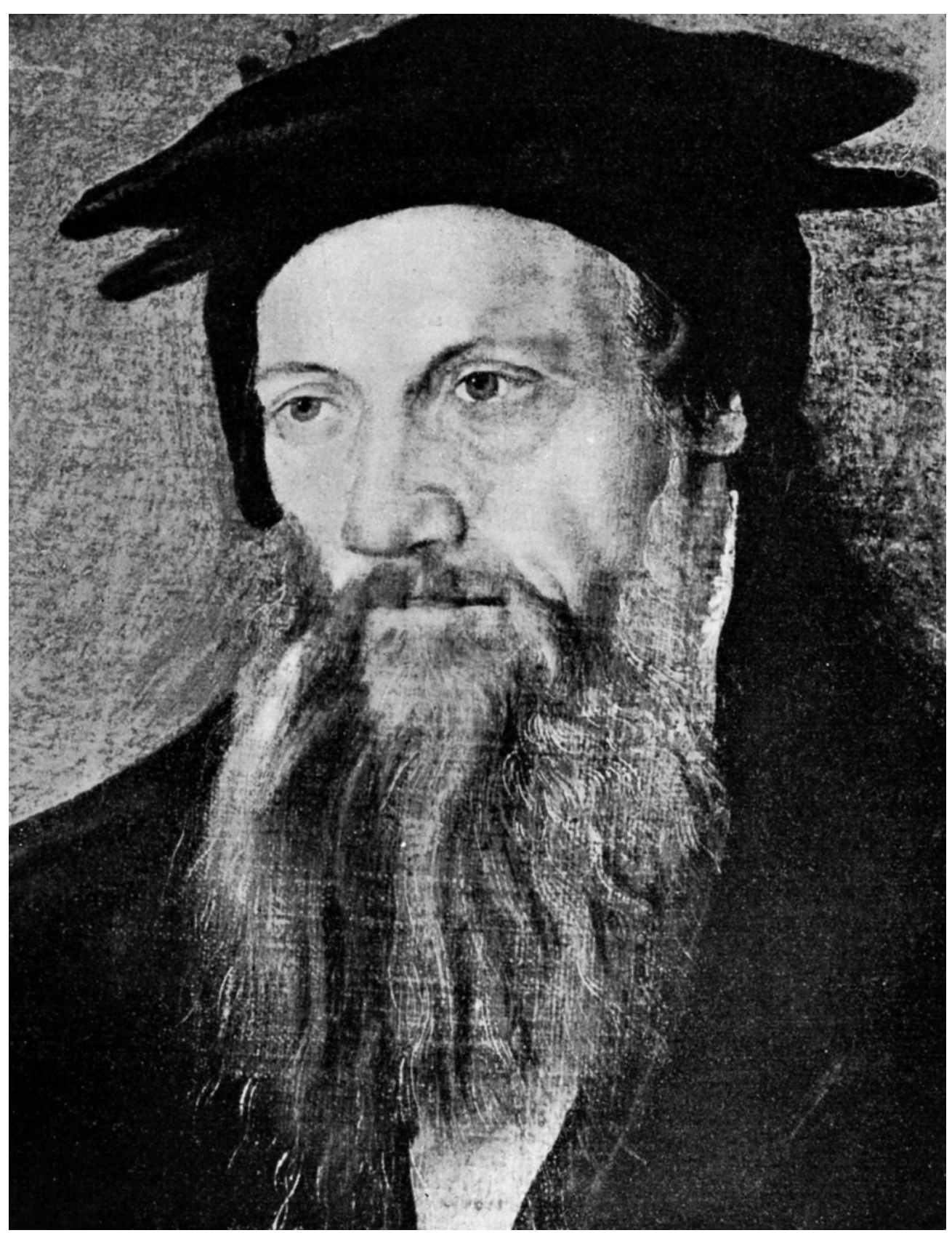

Fonte: Conrad Gessner (2015).

A predisposição para a elaboração de obras bibliográficas, como é o caso de Catalogus Plantarum (1542), levou Gesner ao projeto bibliográfico mais ambicioso da Europa Moderna: Bibliotheca Universalis.

A obra foi publicada em quatro partes, entre 1545-1555: 1) Bibliotheca Universalis, sive Catalogus omnium scriptorum locupletissimus, in tribus linguis, Latina, Graeca, et Hebraica [...] (1545 - 
FIG. 2); 2) Pandectarum sive partitionum universalium [...] (1548); 3) Partitiones theologicae (1549) e 4) Appendix bibliothecae (1555).

De acordo com Malclès (1960), Bibliotheca Universalis, sive Catalogus [...] foi impressa em 1545 por Froschover, em Zurique, em um in-folio de 631 folhas.

Bibliotheca Universalis, sive Catalogus [...] é um catálogo alfabético-nominal que apresenta 5031 autores de obras compostas nas três línguas eruditas, ou seja, latim, grego e hebraico. O catálogo é organizado por ordem alfabética do primeiro nome do autor, mas é acompanhado por uma lista separada e organizada por sobrenomes (SABBA, 2012). A obra também apresenta resumo e extratos dos documentos listados. 


\section{Figura 2 - Bibliotheca Universalis}

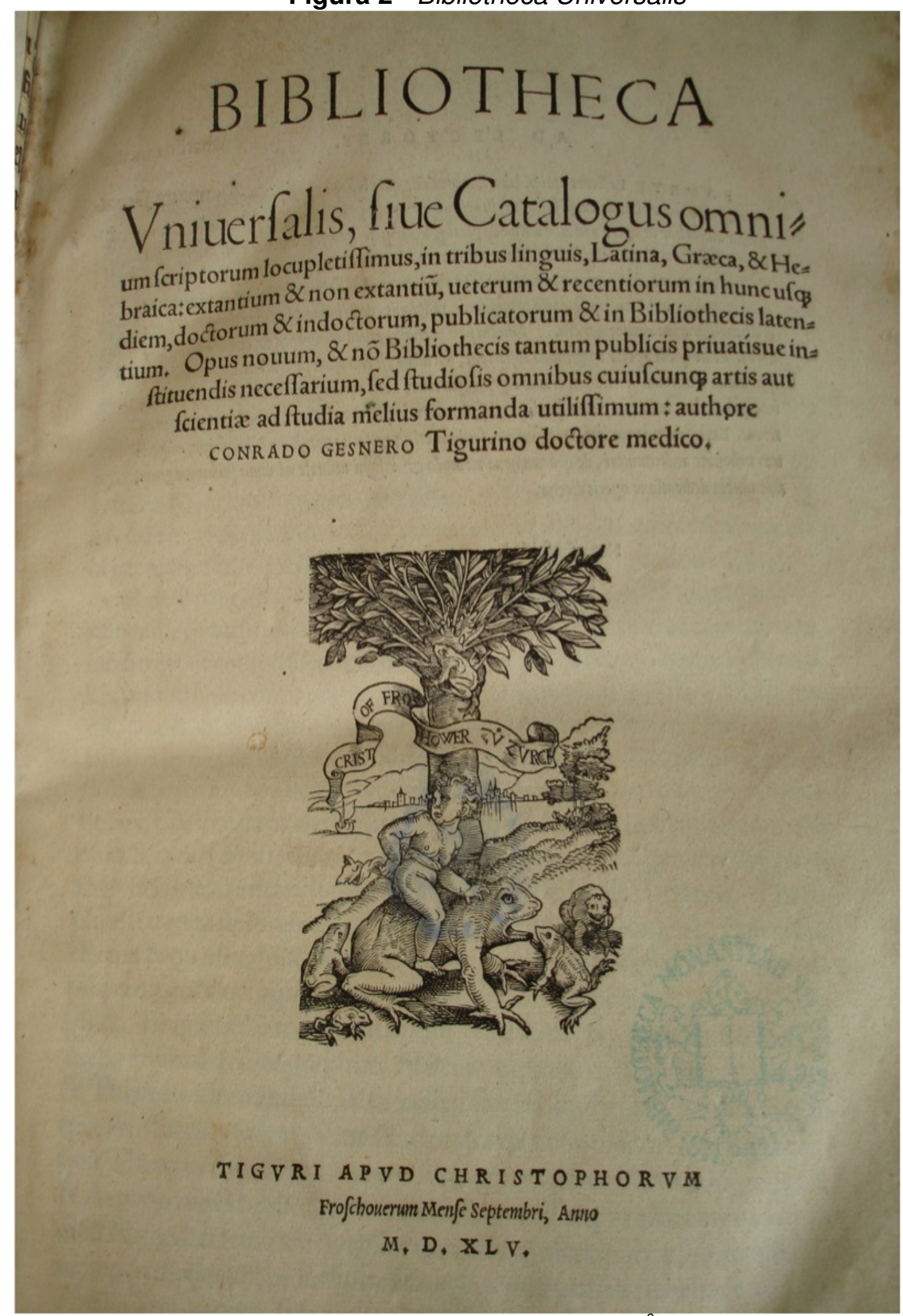

Fonte: Araújo (2008, p. 138)

${ }^{6}$ Exemplar pertencente à Coleção de Livros Antigos da Livraria de São Bento, São Paulo, Brasil. Reproduzido sob a permissão do autor. 
Já Pandectarum sive partitionum universalium... (FIG. 3) foi impresso em 1548, em um in-folio de 374 folhas (MALCLÈS, 1960). Contempla a exposição classificada do material documentário, ou seja, a exposição do conhecimento extraído dos livros da primeira parte. Tratase de um repertório de ordem sistemática.

Inicialmente, o esquema foi concebido em XXI Partições: Pandectarum sive partitionum universalium [...] contempla XIX Partições, de modo que Partitiones theologicae contempla a última Partição, publicada separadamente em 1549 e nomeada Partição XXI. A Partição XX, projetada para apresentar o catálogo semântico das obras de medicina, não foi finalizada (SERRAI, 1990). 


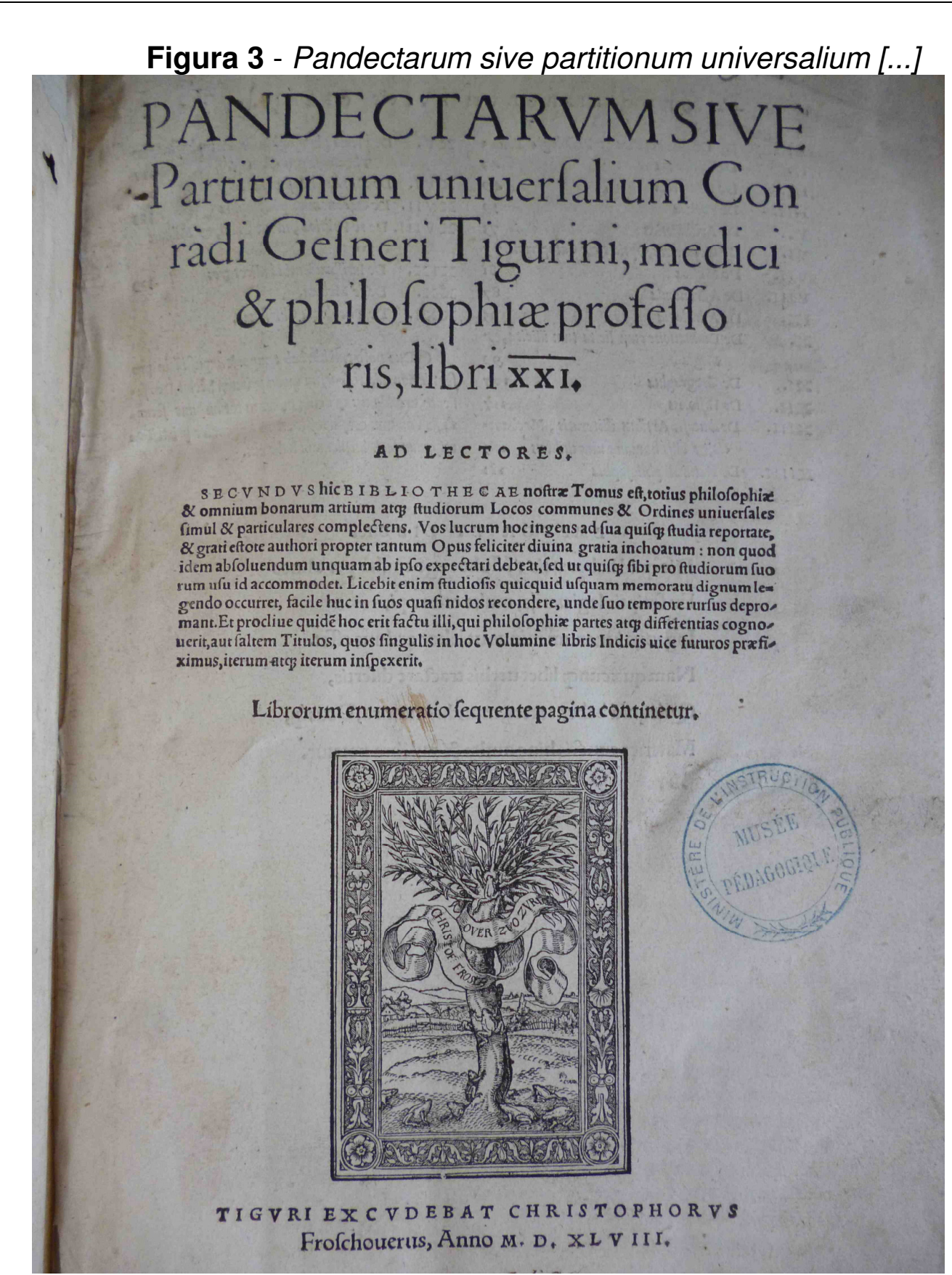

Fonte: Interfaces (2015).

O sistema de classificação em Pandectae advém das sete artes liberais até as categorias de assuntos complementares e de interesse aos estudiosos e eruditos do Renascimento.

O esquema é assim organizado: 1-Gramática (e Filologia), 2Dialética, 3-Retórica (representando o trivium), 4-Poética; 5-Aritmética, 6-Geometria, 7-Música e 8-Astronomia (sendo as últimas quatro classes representadas pelo quadrivium). Estas são seguidos pelas ciências incluindo o currículo universitário medieval: 9-Astrologia, 10-Adivinhação 
e Magia, 11-Geografia, 12-História, 13-Artes Mecânicas, 14-Filosofia Natural, 15-Metafísica, 16-Filosofia Moral, 17-Filosofia Econômica, 18Política; e finalmente, 19-Direito, 20-Medicina e 21-Teologia.

Para Malclès (1960) o sistema de classificação de Gesner é original, uma vez que amplia as sete artes liberais da Idade Média.

Pandectae torna-se 0 primeiro esquema de classificação expressamente projetado para organizar livros. Possui um índice alfabético remissivo de assunto cujas entradas remetem para a classificação codificada de Pandectae (WELLISCH, 1981 apud CUNHA; LIMA, 2008).

Gesner organiza cada obra a partir das categorias previamente definidas e coloca em prática seu pensamento esquemático: na medida em que foi naturalista, ao trabalhar com a classificação dos seres, foi também bibliógrafo, ao trabalhar com a classificação dos saberes. Estava interessado em classificar tanto livros quantos os animais. Assim, promoveu uma espécie de "anatomização" da biblioteca e do conhecimento, sugerindo que o próprio ato de anatomizar dava bases para $o$ ato de classificar.

O que impressiona no exercício bibliográfico gesneriano é que o polímeta leu ou ao menos viu todas as obras que documenta, viajando e consultando múltiplas fontes de pesquisa, em meio à uma época de grandes desafios para o acesso e circulação do impresso.

A bibliografia de Gesner seguiu uma lógica de revisitação às fontes: do mesmo modo que Gesner se apoiou em Johannes Trithemius, bibliógrafos posteriores a Gesner se basearam em Bibliotheca Universalis, como é o caso de Florian Treffler (1483-1565) em sua obra Methodus Exhibens Variorum Indices (1560).

A obra bibliográfica de Gesner confirma o fundamento de que a partir da esfera material e esfera bibliotecária, a Bibliografia se transforma em uma disciplina que se ocupa tanto dos aspectos descritivos quanto dos aspectos semânticos dos documentos, articulando sua fisicalidade e os saberes inerentes a eles. 


\section{BIBLIOTHECA UNIVERSALIS: DISPOSITIVO DE MEDIAÇÃO E MEMÓRIA BIBLIOGRÁFICA}

Viviane Couzinet (2012) afirma que as listas (cuja expressão mais bem sucedida são os repertórios bibliográficos) são dispositivos de mediação e de representação da produção científica e literária, além de serem investidas de uma função memorial.

Em Bibliotheca é possível identificarmos não só o tratamento descritivo/ semântico dado aos documentos, mas também justamente sua dimensão mediadora e memorial.

A obra possui uma função mediadora na medida em que é adotada como guia de referência para formação e desenvolvimento de inúmeras coleções de bibliotecas. Bibliotheca também é utilizada como um verdadeiro catálogo nas bibliotecas, bastando ao bibliotecário indicar a localização física dos livros na própria obra.

Para Capaccioni (2006), Gesner vivia imerso na realidade editorial de seu tempo: colaborava com alguns impressores, frequentava as oficinas tipográficas e visitava bibliotecas. Tais ações situam Gesner naquilo que poderíamos denominar de mediações bibliográficas.

A dimensão mediadora também pode ser observada já que Gesner foi o primeiro bibliógrafo da Europa Moderna preocupado com os livros em si e com o seu uso. Para ele, a elaboração de bibliografias era uma atividade essencial e que se impõe por si mesma (MALCLÈS, 1960).

Uma das maiores motivações para a elaboração de Bibliotheca está no fato de Gesner ter se impressionado quando os turcos incendiaram e saquearam, em 1527, durante o ataque à cidade de Buda, a biblioteca de Matías Corvino, rei da Hungria. Tal fato teria exercido influência sobre Gesner e o fez, mais tarde, trabalhar com o propósito de salvaguardar os testemunhos do pensamento, no caso dos livros desaparecerem (MALCLÈS, 1960).

É aqui que fica evidente o caráter memorialístico de Bibliotheca: ao reunir as obras de 5031 autores, Gesner busca materializar um 
universo bibliográfico amplo e representativo do mapa dos saberes. Seu interesse está nas mediações bibliográficas que Bibliotheca possibilitaria e também na criação de um dispositivo de memória bibliográfica.

Interessante observarmos que também a obra de Gesner passa a ser objeto de lembrança nos estudos bibliográficos e o estatuto dado ao polímeta suíço levaria à sua própria monumentalização, representada pela expressão "pai da Bibliografia".

Este aspecto monumental parece estar vinculado ao caráter intencionalmente universal da obra, afinal o desejo de universidade figura no próprio título da bibliografia.

Do ponto de vista técnico, a obra contempla em torno de um quarto das obras publicadas, mas o que a confere universalidade é:

[...] 0 ato de abarcar todos os conhecimentos sem exceção e de registrar livros de toda procedência. Se vale por sua riqueza (notável para a época, pois se deve ter em conta a dispersão dos livros e a dificuldade de comunicação), vale mais ainda pelo seu espírito. (MALCLÉS, 1960, p. 18).

Os aspectos mediadores e memorialísticos de Bibliotheca a situam, portanto, na dinâmica dos fundamentos da Bibliografia e, consequentemente, na dinâmica dos estudos de documentação e informação.

\section{CONSIDERAÇÕES}

Bibliotheca Universalis é mais do que um produto cultural e documentário: arrola aspectos da cultura manuscrita e impressa e traz implicitamente uma profunda reflexão descritiva e semântica sobre os documentos e os saberes, o que contribuiu sobremaneira à configuração histórica e conceitual da Bibliografia enquanto disciplina.

O exercício bibliográfico gesneriano estabelece uma linha muito próxima e quase atemporal entre as atividades bibliográficas, documentais e informacionais: 0 ato de mapear, registrar e representar 
descritiva e semanticamente os documentos continuam atuais, naturalmente.

Hagar Espanha Gomes (2010) afirma que hoje muito se fala sobre web semântica, taxonomia, classificação automatizada e outros temas que buscam resultados mais inteligentes das buscas na Internet. No núcleo dessas preocupações está a organização do conhecimento, que foi primeiramente representada pela Bibliografia.

Como uma metadisciplina, a Bibliografia, na sua origem, possibilitou o delineamento teórico e metodológico de inúmeros repertórios bibliográficos, dos quais Bibliotheca merece lugar significativo do ponto de vista histórico-documental.

Gesner foi introduzido no quadro da disciplina bibliográfica não só por aprofundar a consciência da estrutura e do conteúdo de sua bibliografia, mas também por recriar minuciosamente uma espécie de "biblioteca", ao fornecer evidências de ordem nominal e semântica.

Documento fundamental para a história das ciências, da cultura e mesmo da literatura, a obra de Gesner de fato se expressa pelo testemunho documental. Este caráter documental está no ato de documentar as obras listadas e, sobretudo, no exercício reflexivo de bibliografia histórica, que nada mais é que uma reflexão de ordem documental.

Portanto, a bibliografia gesneriana suscita uma série de reflexões que dialogam com o contemporâneo; questões que tornam as preocupações de Gesner tão atuais.

Bibliotheca Universalis foi e permaneceu um unicum na história da bibliografia: ninguém, antes ou depois de Gesner, conseguiu criar e publicar um catálogo universal dos escritores e suas obras. A Bibliotheca Universalis gesneriana permanece, portanto, até hoje, a única bibliografia universal que foi dada à luz da invenção da Imprensa. O caráter excepcional da maior obra bibliográfica de Gesner foi percebido e apreciado desde sua primeira aparição; desde o Séc. XVI em diante o repertório gesneriano tem sido procurado avidamente não só por sua raridade intrínseca e preciosidade bibliográfica, mas como referência e 
suporte para criação de bibliotecas e como modelo e guia catalográfico para a sua organização. (SERRAI, 1990, p. 69).

Bibliotheca conjuga mediação e memória bibliográfica, em um jogo entre monumentalidade e desejo de universalidade, além de evidenciar o pioneirismo bibliográfico do polímeta do Séc. XVI.

\section{AGRADECIMENTOS}

Agradeço ao Prof. Alfredo Serrai (Università di Roma "La Sapienza") e à Profa. Fiammetta Sabba (Università di Bologna) por resgatarem e evidenciarem a importância da Bibliografia enquanto disciplina, o que representa uma chave fundamental para os estudos da informação e do documento, hoje. Suas reflexões foram basilares para o desenvolvimento deste trabalho, apresentado no I Seminário Internacional "A Arte da Bibliografia: ferramentas históricas, problemas metodológicos e práticas contemporâneas" ", em 04 de dezembro de 2014, na Universidade Federal do Rio de Janeiro (UFRJ).

\section{REFERÊNCIAS}

ARAÚJO, André de. Dos livros e da leitura no Claustro: elementos de história monástica, de história cultural e de bibliografia histórica para estudo da Biblioteca-Livraria do Mosteiro de São Bento de São Paulo (Sécs. XVI-XVIII). 2008. 343 f. Dissertação (Mestrado em História Social) - Universidade de São Paulo, São Paulo, 2008. Disponível em: <http://www.teses.usp.br/teses/disponiveis/8/8138/tde-10022009124405/pt-br.php>. Acesso em: 30 jul. 2009.

BOWERS, Fredson. Principles of bibliographical description.

Princeton: Princeton University Press, 1949. 
BUCKLAND, Michael Keeble. What is a document? Journal of the American Society for Information Science, New York, v. 48, n. 9, p. 804-809, 1997.

CAPACCIONI, Andrea. Mapas y memorias: apostillas a una historia de la Bibliografia. Documentación de las Ciencias de la Información, Madrid, v. 29, p. 9-24, 2006.

CHARTIER, Roger. A ordem dos livros: leitores, autores e bibliotecas na Europa entre os séculos XIV e XVIII. 2. ed. Brasília: Universidade de Brasília, 1998.

CONRAD GESSNER. In: Wikipédia. 2015. Disponível em: <https://en.wikipedia.org/wiki/Conrad_Gessner>. Acesso em: 10 fev. 2015.

COUZINET, Viviane. Fabrique de la liste: dispositif entre mémoire et commémoration. In: JORNADA CIENTÍFICA INTERNACIONAL REDES E PROCESSOS INFO-COMUNICACIONAIS: MEDIAÇÕES, MEMÓRIAS, APROPRIAÇÕES (REDE MUSSI), 2., 2012, Rio de Janeiro Anais... Rio de Janeiro: Rede Mussi, 2012. p. 132-149.

CRIPPA, Giulia. Entre ciência e humanidades: o problema da ordem da memória da/para a Ciência da Informação. In: ENCONTRO NACIONAL DE PESQUISA EM CIÊNCIA DA INFORMAÇÃO, 11., 2010, Rio de Janeiro. Anais... Rio de Janeiro: IBICT, 2010. Disponível em: <http://enancib.ibict.br/index.php/xi/enancibXl/paper/view/40>. Acesso em 10 jun. 2012.

CUNHA, Murilo Bastos da; LIMA, João Alberto de Oliveira. Tratamento da informação legislativa e jurídica: perspectiva histórica. Senatus: Cadernos da Secretaria de Informação e Documentação, Brasília, v. 6, n. 2, p. 33-38, out. 2008.

FARIA, Maria Isabel; PERICÃO, Maria da Graça. Dicionário do livro: da escrita ao livro eletrônico. São Paulo: EDUSP, 2008.

GASKELL, Philip. A new introduction to Bibliography. New York: Oxford University Press, 1972.

GOMES, Hagar Espanha. Longa caminhada no tratamento semântico de documentos. In: FREITAS, Lídia Silva de; MARCONDES, Carlos Henrique; RODRIGUES, Ana Célia. (Org.). Documento: gênese e contexto de uso. Niterói: EDUFF, 2010. p. 193-204.

GREG, Walter Wilson. What is bibliography. In: MAXWELL, James Clerk. (Ed.). Collected papers. Oxford: Clarendon Press, 1966. 
INTERFACES. La gestion de l'information au XVle siècle (2/2): la bibliographie universelle de Conrad Gesner. Notas Bastien Rissoan. Disponível em: <http://bibulyon.hypotheses.org/4825>. Acesso em: 10 fev. 2015.

JACOB, Christian. Ler para escrever: navegações alexandrinas. In: BARATIN, Marc; JACOB, Christian. (Org.). O poder das bibliotecas: a memória dos livros no Ocidente. Rio de Janeiro: [s. n.], 2000.

LEO, Urs B.; KELLER, Raffael; WEIDMANN, Sandra. Conrad Gessner's private library. Leiden: Brill, 2008.

LUND, Niels Windfeld. Document theory. Annual Review of Information Science and Technology, White Plains, v. 43, n. 1, p. 155, 2009.

MALCLÈS, Louise Nöelle. La bibliografía. Buenos Aires: EUDEBA, 1960.

MCKENZIE, Donald. F. Bibliography and the sociology of texts. Cambridge: Cambridge University Press, 1999.

ORTEGA, Cristina Dotta; LARA, Marilda Lopes Ginez de. A noção de documento: de Otlet aos dias de hoje. DataGramaZero: Revista de Ciência da Informação, Rio de Janeiro, v. 11, n. 2, abr. 2010. Disponível em: <http://www.dgz.org.br/abr10/Art_03.htm>. Acesso em: 28 mai. 2014.

RICHÉ, Pierre. As bibliotecas e a formação da cultura medieval. In: BARATIN, Marc; JACOB, Christian. (Org.). 0 poder das bibliotecas: a memória dos livros no Ocidente. Rio de Janeiro: Editora, 2000. pt. 3, p. 246-256.

SABBA, Fiametta. La 'Bibliotheca Universalis' di Conrad Gesner: monumento della cultura europea. Roma: Bulzoni Editore, 2012.

SERRAI, Alfredo. Analecta libraria: tema di critica bibliografica e di storia bibliotecaria. Editado por Maria Grazia Ceccarelli. Roma: Bulzoni, 2000.

Biblioteche e bibliografia: vademecum disciplinare e professionale. Editado por Marco Menato. Roma: Bulzoni, 1994. . Il cimento dela bibliografia. Milano: Sylvestre Bonnard, 2001. . Conrad Gesner. Roma: Bulzoni, 1990.

. Johannes Trithemius. In: Storia della bibliografia VII: storia e critica della Catalogazione Bibliografica. Roma: Bulzoni, 1997. v. 7, p. 51-59. 
Natura elementi e origine della bibliografia in quanto mappa del sapere e dele lettere. Roma: Bulzoni, 2010.

THOMPSON, James Westfall. The medieval library. Chicago: University of Chicago Press, 1939.

\title{
Title
}

Bibliographical pioneering in a polymath of the 16th Century: Conrad Gesner

\begin{abstract}
Introduction: The Bibliography is a discipline constituted by practical and theoretical interfaces that, since its origin, has founded the documentary treatment. Has a long history, whose eminence is the contributions of the scientist, scholar and bibliographer swiss, Conrad Gesner (1516-1565), and his work Bibliotheca Universalis.
\end{abstract}

Objective: 1) identify the interfaces of the Bibliography, notably the librarian and material; 2) recover constitutive elements of bibliographical culture; 3) delineate the bio-bibliographical profile of Conrad Gesner; 4) identify, in summary form, bibliographical aspects of Bibliotheca Universalis, from the descriptive and semantic point of view; 5) discuss its meaning as an apparatus of mediation and bibliographical memory.

Methodology: literature review from the historical perspective.

Results: Gesner is one of the greatest scientists of the modern period, and is considered the "father of Bibliography" and founder of bibliographical discipline. With Bibliotheca Universalis, outlined the bibliographical practices of Modern Europe.

Conclusions: Bibliotheca Universalis is more than a cultural and documentary product: enrolls aspects of the print and manuscript culture and implicitly brings a deep reflection about documents and knowledge. These aspects not only contribute to the historical and conceptual configuration of the Bibliography as a discipline, but, mainly, show the bibliographical pioneering of the polymath of the 16th Century.

Keywords: Bibliography - history and theory. Bibliographers - History. Bibliotheca Universalis - 16th Century. Conrad Gesner - 1516-1565. Bibliographical culture.

\section{Titulo}

Pionerismo bibliográfico en un polímeta del siglo XVI: Conrad Gesner

\section{Resumen}

Introducción: La Bibliografía es una disciplina que consiste en interfaces teóricas y prácticas que, desde su origen, ha fundado el tratamiento documental. Tiene una larga historia, cuya eminencia es en las contribuciones 
del científico, erudito y bibliógrafo suizo Conrad Gesner (1516-1565), y su obra Bibliotheca Universalis.

Objetivo: 1) identificar las interfaces de la Bibliografía, en particular la bibliotecaria e material; 2) recuperar elementos constitutívos de la cultura bibliográfica; 3) trazar el perfil biobibliográfico de Conrad Gesner; 4) identificar, en forma resumida, los aspectos bibliográficos de Bibliotheca Universalis, desde el punto de vista descriptivo y semántico; 5) discutir su significado como un dispositivo de mediación y memoria bibliográfica.

Metodología: revisión de la literatura desde la perspectiva histórica.

Resultados: Gesner es uno de los científicos más notables de la época moderna, además de ser considerado como el "padre de la Bibliografía" y fundador de la disciplina bibliográfica. Con Bibliotheca Universalis, esbozó las prácticas bibliográficas de la Europa Moderna.

Conclusiones: Bibliotheca Universalis es más que un producto cultural y documental: ofrece aspectos de la cultura manuscrita y impresa y implícitamente trae una profunda reflexión descriptiva y semántica acerca de los documentos y conocimientos. Estos aspectos no sólo contribuyen a la configuración histórica y conceptual de la Bibliografía como disciplina, pero, especialmente, muestran el pionerismo bibliográfico del polímeta del siglo XVI.

Palabras-clave: Bibliografía - historia y teoría. Bibliógrafos - historia. Bibliotheca Universalis - siglo XVI. Conrad Gesner - 1516-1565. Cultura bibliografica.

Recebido em: Abril de 2015

Aceito em: Julho de 2015 